\title{
Information Materialities of Citizen Communication in the U.S. Congress
}

SAMANTHA MCDONALD and MELISSA MAZMANIAN, University of California, Irvine, USA

In this paper, we use a materiality lens to explore how information and communication technologies condition interaction between citizens and policymakers of the U.S. Congress. We work with ethnographic data - six months of observation in Washington D.C. and 48 interviews with staff in the House of Representatives. Customer relation management systems (CRMs) used by Congress are one of numerous technologies expected to enhance responsive communication between citizens and representatives. We find, instead, that these technologies promote the datafication of citizen information that configures and constrains how policymakers engage citizens as legitimate actors within the policy-making process. CRMs not only mediate communication between citizens and policymakers, they shape the idea of what communication between citizens and policymakers can be and how citizens are viewed in the eyes of policymakers and their staff. Thus, we extend our understanding of the ways in which material configurations of communication technologies influence not only how communication acts unfolds, but also how each partner conceives of and engages with the other. This has dramatic implications for the possibilities of digital communication channels to enhance, or uphold, the ideals of a representative democracy.

CCS Concepts: • Social and professional topics $\rightarrow$ Governmental regulations.

Additional Key Words and Phrases: Materialities; Civic Communication; Representation; Policy; HCI; Congress; Government

ACM Reference Format:

Samantha McDonald and Melissa Mazmanian. 2019. Information Materialities of Citizen Communication in the U.S. Congress. Proc. ACM Hum.-Comput. Interact. 3, CSCW, Article 47 (November 2019), 20 pages. https://doi.org/10.1145/3359149

\section{INTRODUCTION}

There has been an increase of attention in the field of CSCW, and HCI broadly, towards the relationships between technology, policy, and democracy. This stream of scholarship recognizes that communication is a central component to democracy, and information and communication technologies (ICTs) are changing practices of civic engagement and governance [5,63]. Such growth is clearly demonstrated at the most recent CSCW conference where three different paper sessions explored civic engagement, social movements, and citizen science [61]. The field has become increasingly interested in understanding how technology affects civic life and governance through different means of communication.

Despite this growth, however, minimal attention has been directed towards understanding the role of technology in the daily operations of government offices, particularly those of elected

Authors' address: Samantha McDonald, smcdona2@uci.edu; Melissa Mazmanian, mmazmani@uci.edu, University of California, Irvine, Irvine, California, USA, 92617.

Permission to make digital or hard copies of all or part of this work for personal or classroom use is granted without fee provided that copies are not made or distributed for profit or commercial advantage and that copies bear this notice and the full citation on the first page. Copyrights for components of this work owned by others than ACM must be honored. Abstracting with credit is permitted. To copy otherwise, or republish, to post on servers or to redistribute to lists, requires prior specific permission and/or a fee. Request permissions from permissions@acm.org.

(C) 2019 Association for Computing Machinery.

2573-0142/2019/11-ART47 \$15.00

https://doi.org/10.1145/3359149

Proc. ACM Hum.-Comput. Interact., Vol. 3, No. CSCW, Article 47. Publication date: November 2019. 
representatives. It is important to understand how ICTs might be changing the nature of communication that plays into the relationship between citizen input and policymaker action. In order to sustain itself, a representative democracy must foster engaged communication between citizens and those that represent them in governing bodies. Scholars speculate that the nature of representative communication is changing due to the emergence of ICTs that provide increasing opportunities for citizen-policymaker engagement $[10,22,49]$. Thus, it behooves us to empirically understand technologies that are already central to the communication practices of elected representatives. If we recognize that the acts of communication, as central practices in representative democracy, are conditioned by technologies, the stakes of this analysis become clear. The everyday instantiations of democracy are played out through technologies that mediate the relationships between citizens and their policymakers.

To explore the effects of technology on representative communication, we investigate how offices of Members of the U.S. Congress (referred to as Members) use customer relation management systems (CRMs). These systems are used to maintain information about citizen correspondence such as information about in-person meetings, phone calls, emails, postal mail, fax, and social media. To investigate CRMs, we leverage a material lens to explore how the material configurations of information in the technologies shape Member's engagement with citizens. We build on recent work around information materialities, and the consequential ways in which information is represented in communication platforms $[14,15]$. CRMs are the primary mediators of all communication between Members of Congress and citizens. We investigate these systems as material artifacts that shape, constrain, and enable certain communication practices and representations of citizens in the eyes of policymakers.

Using ethnographic fieldwork of the U.S. Congress, we find CRMs promote an anaemic form of engagement between citizens and their representatives. Citizens are reduced to predefined data points to satisfy the informational needs of the CRM. Rather than promoting the engaged communication called for in scholarship on representative democracy, the use of CRMs (within the institutional context of Congressional offices) enables a superficial tracking of citizen input. The ways in which CRMs log and manage information about citizen communication creates discursive expectations that prioritize data-collection over substantive engagement. In so doing, the citizen is rendered into a data point that can be quantified by the offices of Members to obtain the general sentiment of the district. This data is used to measure overall performance of the Member's office, with little influence to Member's policy decisions. CRMs also promote customer-oriented engagement in which staff prioritize assuaging citizens' concerns over seriously considering their input. Taking a material lens on the role of CRMs reveals how particular communication systems participate in reshaping citizens into customers and data points. Therefore, CRMs limit the possibility for citizens to be recognized as legitimate actors within the policy-making process.

\section{BACKGROUND AND RELATED WORK}

Research at the intersection of technology, policy, and democracy is growing in HCI. Scholars have developed platforms for civic engagement and public deliberation [39], tested systems to encourage involvement in citizen-science $[7,36,56,58,66]$, and fostered participatory design and decision-making opportunities in local communities [52, 53, 69]. Observations of governmental service workers and service users have been used to explore relationships between bureaucratic organizations and citizens, and to develop frameworks for values and conflicts within e-government $[12,13,26,64]$. Studies of social movements explore the effects of digital technologies on protest and boycotts $[2,42]$. Lastly, broader conversations within the community encourage the field to take part in real policy-making [31, 41, 62] and studying the effects of policy on the field's research $[27,30,35]$.

Proc. ACM Hum.-Comput. Interact., Vol. 3, No. CSCW, Article 47. Publication date: November 2019. 
Despite this growth, minimal attention has been directed toward elected policymakers. Only a handful of studies in HCI have looked to policy-makers (e.g., [6, 23, 28, 37, 43]). CSCW has offered great perspectives on the use of technology in civic participation, including public officials (e.g., [12]), but none have explored the internal practices of elected representatives. The only studies available looked towards external indicators such as social media post by representatives and citizens $[23,28]$. Nearly all work investigating representative technology is taking place outside $\mathrm{HCI}$ in fields such as political science and e-government. Across disciplines, there is a notable lack of attention to how policymakers and their staff engage with digital technology in the course of everyday work. Even in political science research on Congress, scholars have noted how little we know about the everyday practices of policymakers and their communication processes with citizens [1]. Thus, this area is very much under-explored.

Despite the dearth of research, the internal communication practices of representatives are critical to fundamental notions of democratic representation. From a normative perspective, it is vital for policymakers to engage with the needs and desires of the public in order to create policy that is responsive to their concerns [54]. Citizen-centric theories of representation assume that communication between citizens and representatives is critical to a policy-making process that represents the needs of the populous [49]. This communication with citizens also offers representatives the ability to obtain, discern, and respond to constituent request and policy opinions, and inform constituents of their actions and policy [44]. Thus, open communication channels - in service of both re-elections and policy-making - are defining characteristics of elected representatives and critical components to the practices of representative democracy.

Ideally, the array of emerging communication technologies that have taken off in recent decades should provide opportunities for citizens to collaboratively engage with policymakers in policy creation and decision-making. There is ample discussion on how new ICTs are reconfiguring representation and participation in a broad range of political context (e.g., $[4,8,11,25,46])$. Within the congressional research community, there is a growing belief that this rise in communication channels will offer increasingly inexpensive and unmediated pathways for citizens to communicate policy preferences and express support or grievances with Members [16]. In return, direct access to citizen information and preferences is thought to provide more accountability and responsiveness to representatives $[40,59]$. This narrative supports the promise that communication technologies can transform democratic representation by giving more power to voices of citizens.

That said, empirical evidence challenges this narrative. Members use social media platforms for self-promotion and stating policy positions [22, 23,47]. There is evidence that citizen contact is primarily used to formulate proforma response messages and public media for the Members. And there is no clear indication that citizen input mediated through digital platforms is considered in policy-making decisions $[1,19]$. However, no study of Congress has interrogated the technology which play a role in mediating communication between citizens and policymakers, and how these systems shape the practices of democratic representation. This paper asks how the communication technologies used by Members and their staff actually affect the ways in which Members relate to citizens in the policy-making process.

\subsection{ICT in Congress}

The U.S. Congress is the legislative arm of the federal government of the United States. They are responsible for developing and passing laws to govern the country. Congress is a collection of 535 democratically elected representatives of different states and districts. There are two senators for each state and 435 representatives for each district (not including the six non-voting Members) All Members provide a number of communication channels for their citizens that live in their electoral districts to contact their offices. These channels include in-person meetings, town halls,

Proc. ACM Hum.-Comput. Interact., Vol. 3, No. CSCW, Article 47. Publication date: November 2019. 
letters, phone calls, email, fax, and social media. In turn, citizens reach out to their Members in an attempt to influence their policy decisions, seek assistance with government issues, and express their personal opinions. These channels are also frequently used by advocacy groups to lobby policymakers to request actions by the Members.

The breadth of digital communication between citizens and Members' offices is continuously growing. Citizen communication to Members' offices has reportedly increased 200-1000\% over the past decade [24], with anecdotal evidence saying those numbers are even larger over the past few years. Historically CRMs, which are the focus of this analysis, emerged out this growing use of digital communication. In 1911, nearly all citizens contacted their Members through in-person meetings, postal mail, and telephone [51]. In 1993, Congress experimented with email, and by 1995 , provided publicly available emails to each Member [29]. This new mode of communication changed the means by which Members' offices communicated with citizens. As citizens began to take part in large-scale coordinated advocacy campaigns, the volume of email increased beyond the capacities of Member offices to manage [29]. In the mid-2000s, a new industry of technology vendors emerged to help coordinate digital advocacy campaigns that inundated the Member's emails and websites, often with redundant form-based letters sent through one-click advocacy request (see discussions by $[34,60])$. Congress responded by deploying new systems such as captcha, IP blocking, and CRMs. Thus, CRMs emerged out of a need to manage an influx of information and communication with citizens. Today, as communication by citizens and advocacy groups to Members continues to increase, CRMs remain the primary medium for all communication that comes into the offices of Members.

2.1.1 Customer Relations Management Software. CRMs, also called constituent management systems and constituent databases, are used to manage constituent communication. CRMs function as both channels for communicating with citizens and databases to log, track, and categorize incoming contact. When a person calls a Member's office, attends a meeting with a Member, sends an email, postal mail, fax, or social media post, that information can be logged into the CRM. The CRM also allows Members to respond to citizens through the system via email or printed letters.

CRMs are provided by external vendors. These vendors are approved separately in the House and Senate Chambers of Congress. In the House, the Chief Administration Officer (CAO), Office of Acquisition approves all software procurement and negotiates prices options. In the Senate, it is the Office of Senate Sergeant at Arms [65]. Currently there are two vendors in the House that control more than $70 \%$ of all CRM use by Members. These vendors are called Intranet Quorum (known as IQ) and Fireside21. There are only a handful of other vendors approved, making CRM selection limited. Members initially choose their vendor at vendor fairs after being sworn-in and setting up their office. Given that Members are also dealing with a myriad of other decisions to get their offices up and running, while at the same time learning the rules and procedures for being a Member of Congress, the decisions need to be made quickly.

Processing citizen contact in the CRMs is almost exclusively performed by the Members' communication staff. These staffers are expected to answer, listen, respond, and organize all incoming citizen contact. They use CRMs to collect, store, analyze, and share citizen information with the rest of their staff. Staff can also use CRMs to send reply letters to citizens, develop communications reports, deploy surveys to gain feedback from citizens, and maintain a record of citizen information.

\subsection{Materialities of Information}

We use a lens of materialities to interrogate how CRMs affect citizen-policymaker communication. Throughout many fields there are various definitions and approaches to materiality. In CSCW, a lack of definition is a defining characteristic of materiality [57], but it is generally acknowledged 
as embodying the physical implemented within interactions with the digital, where the material components of technology can have a profound effect on human conduct. Materiality is the nature and properties of things that constrain and condition the forms of social action taken around them. Thus, there are components of any digital system that make themselves known through physical interactions. Materiality also recognizes a recursive relationship between material conditions and social arrangements, highlighting Orlikowski's notion of constitutive entanglement between work practice, organizational form, and technological systems [50]. Thus, taken together, the material conditions of CRMs and the institutional practices of Congress play a strong role in how Members and their staff understand what constituent communication is and should be.

This paper explores the materialities of information that reside within digital things. These information materialities are the "properties of representation and formats that constrain, enable, limit, and shape the ways in which those representations can be created, transmitted, stored, manipulated, and put to use" $[15$, p.6]. For example, studies of organizational practice show how the specific informational structures of PowerPoint (e.g. bullet point mode of presentation) enable certain kinds of communication, acting as both a site of collaboration and boundary drawing in the context of strategic decision making under uncertainty [33, 68]. In a similar vein, scholarship has shown how the material structures of online spreadsheets (the grid and its concomitant alignments, separations, boundaries and implicit relationships) can serve to mediate priorities and competing interests in long term scientific planning. In both of these cases we see how the information structures of a tool serve to delimit, frame, and shape how information is understood and acted upon in the context of organizational life.

This lens allows us to take into account the ways in which information takes on it's own material properties in digital systems. In our case, the CRMs layout, design, and use play an agentic role in configuring information about citizen contact that is documented in the CRMs, thus affecting communication between Member and citizen. We identify how the design and representational properties of CRMs shape not only what information is captured during communication episodes between citizens and Member offices, but also how the information is categorized, understood, and put into practice by Members and their staff. This frame recognizes that CRMs not only collect, $\log$, and store communication, they shape the idea of what communication between citizens and policymakers can and should be.

We draw on two concepts of information materialities highlighted by Dourish and Mazmanian: the materialities of information representation and the material conditions of information technology production [15]. Materialities of information representation call attention to how material forms of information are represented as digital data. How data is shaped configures what questions can be asked of it and how it can be used to understand the world. We show how the material forms of the CRMs and their representational strategies affect how citizen information is captured and used by Members. Thus the form citizen data takes in the CRMs shapes how Members see citizens. Secondly, we identify the material conditions of information technology production. This includes the host of external elements that make the technology work such as the labor infrastructures. We discus the customer-driven design of CRMs and the labor infrastructures that surround the information production through which CRMs are made to work. Staff labor and institutional expectations around citizen-Member communication are part of the maintaining infrastructure that enable CRMs to function in particular ways. These insights emerged though our interviews and observations of staff communication practices vis-à-vis CRMs. 


\section{METHODOLOGY}

Our investigation of CRMs is based on ethnographic fieldwork in the U.S. Congress House of Representatives. The first author performed this fieldwork in Washington D.C. during two threemonth intervals in the summers of 2017 and 2018 and intermittent engagement with Congress over the course of two years. To establish rapport and create connections in Congress, she worked for a congressional non-profit that works directly with Members and their staff. In this role she observed, interacted and interviewed staff; performed data analysis for different Members; and took part in meetings with staff. She also observed presentations on CRMs; met with CRM developers; attended multiple congressional technology conferences; and collected artifacts and materials describing congressional use and procurement of CRMs.

Our research was primarily focused on Members' staff. Staff are tasked with listening to citizens, logging citizen input, and creating aggregate measures of citizen concerns. They are the primary users of the CRMs, with Members rarely engaging in the process of managing citizen communication. Staff are also essential influencers to the Member's views and policy decisions.

Our interviews with staff were conducted in three stages. The first stage of interviews used a convenience sample of 13 staff and interns close to the non-profit where the lead researcher worked. These interviews lasted 45 minutes to an hour. Interns were included because they are often the front lines of all incoming communication to the Member's office. They work with Legislative Correspondents (LCs) staff, the primary correspondence staffers, to manage all contact. During the academic year, we recruited four interns through self-selection from a university-run program to send college students to D.C.

Once the lead researcher returned to D.C. the following summer, she conducted thirty interviews with staff and interns. To gather a diverse and robust data set, we performed recruitment through a randomized list of 100 offices, where the lead research reached out in-person to each office to request an interview. This recruitment was performed in August during recess of the House. When Congress is in recess, there are no votes and Members return to their district. While Members are away, staff in D.C. are often under less pressure - making this period an optimal time to request interviews. Given the highly political nature of Congress, acceptance of interviews was low with only 26 offices accepting interviews. Most of these interviews were conducted immediately following the request, with staff providing 10-25min windows for interviews. Four additional interviews were completed through continued networking. Those additional interviews lasted an hour.

We also include a publicly recorded interview with a current staffer discussing citizen communication at a public media festival. This staffer was interviewed later in-person, but provided valuable information in their public discussions. The final data set includes - by approximate order of seniority - nine interns, twenty-seven legislative correspondents/staff aides (LCs/SAs), four Legislative Assistants (LAs), two Communications Directors (CDs), and five Deputy Chiefs of Staffs and Chiefs of Staff. The data set emphasizes correspondence staff (LC and interns) while accounting for other staff perspectives within the Members' offices. $40 \%$ of the staff interviewed were Republican while $60 \%$ were Democrat. A total of 41 Member of Congress were represented in this sample, with four offices having more than one staffer in the office interviewed.

The goal of every interview was to collect information on how the staff describe their office's correspondence process and what the process meant to the staffer. This occurred through semistructure interview questions where staff were asked to walk-through the correspondence process and describe how that process related to the broader goal and practices of the office. Insights into CRM use were also developed through everyday interactions with staff around Capitol Hill and how they informally discussed correspondence. 
Due to security concerns about sensitive citizen data, many staffers did not feel comfortable being observed while using CRMs. They were, however, willing to describe the system and their processes in detail. In order to gain a robust account of the CRM design, we contacted two CRM vendors that distributed the majority of CRMs used by the House. One of the CRM vendors provided a full demo of the software. Both vendors offered detailed information about their systems and their experiences with staff that use them.

The data extracted from fieldwork notes and interviews were analyzed iteratively over the course of a year using qualitative coding [45]. In the first full round of data analysis, we focused on open-coding salient discussions about the technology and its relationship to their correspondence process. In the second round of data analysis, we focused on drawing out themes related to these connections between the CRMs and correspondence practices, highlighting connections between how information is captured and stored and how it is processed. Subsequent rounds of analysis helped organize themes into corresponding ideas around the materialities of information representation and material conditions of ICT production.

\section{FINDINGS}

We locate our findings in the context of three moments during Member-citizen communication where the materiality of the CRMs and its relation to representation of citizen information come into relief. These moments are during the input of citizen information, the transformation of that information into data for analysis, and the production of written responses to citizens. We begin to see how the CRMs shapes the discursive expectations of how staff communicate with citizens, how citizen input should be understood, and staffs' accepted response to citizen contact.

\subsection{Inputting Citizen Information}

We begin by identifying the relationship between the forms of input expected by CRMs and the main concerns of staff while interacting with citizens. During interviews, staff describe how the CRMs inform the information collected from citizens. Staff are focused on eliciting three primary pieces of information from every citizen who contacts their Member's office: name, address, and reason for contact. A name is required for identification of the citizen and to create a profile in the database. Home address is used for authentication purposes. Staffers are expected to clarify whether citizens are part of the Member's constituency before logging additional information about the contact,

P21: "If you don't put your address and your email address, we can't identify you...that's zero. It's not worth anything because unless it goes in [the CRM] it doesn't get counted...It does not count because we don't know who these people are and we don't know if they're from Kansas or they're from California and we [only] listen to the people that elected our Member of Congress..."

P10: "We got their information in, and if [citizens] were like 'Oh I'm from [out of state]', whatever notes we'd take, we'd just scrap them and say 'Thank you for calling, I'll try to get the message to the Congressmen' and hang up and not do anything else..."

The third piece of information collected is the reason for the contact. The staffer is expected to document, with minimal elaboration, the reason for contact. Reasons given by citizens might include the desire to discuss casework, announce position on a bill, speak on behalf of an advocacy campaign, or complain about an event or policy.

The focus on gathering name, home address, and reason for contact is directly linked to the CRM design. The information prioritized by staff are also, not surprisingly, the field requirements for the CRMs database record. Although the system does provide an open field for notes, our data suggest

Proc. ACM Hum.-Comput. Interact., Vol. 3, No. CSCW, Article 47. Publication date: November 2019. 
that staffers are not populating this field with substantive information. In sum, staffers are neither seeking or logging information that does not satisfy the three principal fields. One could postulate that other information such as the citizen's professional or civic associations and experiences could provide evidence of expertise and knowledge about a topic. However, this sort of information is not asked for by the system and thus not seen as necessary by staffers.

Staff collect name, address, and reason for contact from citizens as quickly and efficiently as possible. Efficiency is necessary to keep up with the constant flow of contact coming from citizens, especially during high salience issues. Staffers report receiving 1,000 campaign letters a week, 400 faxes a day, and 200 phone calls a day during 'hot topic' issues like healthcare or gun control policy. Staffers are deterred from collecting more information or having lengthy discussions with citizens because such conversations take time and distract them from completing the citizen's contact record in the CRM.

The rigidity of collecting only the pieces of information deemed necessary by the system becomes clear when staff describe the process of communicating with citizens. Staff dichotomize citizens into those who "know the drill" and those who don't. And, not surprisingly, they appreciate interacting with people who understand what they need to log during the call.

P8: "Yeah most people know the drill. Most people are very straight forward. And they say exactly what they want to say and then they go."

P2: "There are two categories of constituents: People who call a lot. They know the drill, they know to give their name, address, and what they are calling about. They keep it pretty straightforward. People who call for the first time who really want to talk a lot. Sometimes I have to get the name/ address out of them mid-conversation."

Given the information requirements of the CRMs, conversations between staff and citizens center around the information needs of the system. By asking the citizen to state their name and address mid-conversation, the staffer is demonstrating how CRMs creates discursive expectations, moulding conversations between citizens and policymakers into a procedural task of data input. CRMs reconfigure the ways in which staffers think they should treat citizens while communicating with them. The value of those conversations for the Member is constrained by informational needs of the technology.

Normative conceptions of democratic deliberation assume that citizens should provide reasons for their opinions in order to persuade policymakers to take certain action. Further, policymakers should take citizen reasoning into account when making decisions. Given these ideals, one might imagine that the third piece of information prioritized by staff - the reason for the call- would be the most critical field. This field could be used to create a record of reasons given by citizens to persuade their Member to take certain action. However, we find that this is not the case. Rather, the reason for the contact is more pertinent to the staffer than the logics, expertise, or opinions underlying that reason. In the language of staffers:

P2: "The most effective communication is clear and concise... I don't need to hear why [a person cares about an issue]."

P26: "...seeing what's on people's mind is more valuable than the content [of citizen opinion]."

P10: "Because we always had to do a brief summary of whatever the content was, usually it was just pro/con this bill or this thing. So, you know there is 'Bill X' coming. Read [the letter] and be like, 'Pro Bill X' comma [sic], and brief description like 'pro-gun control'. We would just give a super brief message. Especially if it's something that we're getting a lot of mail about." 
Staff are only documenting the coarsest of information about why a citizen is calling (e.g., which issue, pro/con). They are not interested in collecting information as to why the citizen cares about an issue or whether they are well informed.

4.1.1 Batching. The categorizing function of CRMs also encourage a surface understanding of the impetus underlying citizen contact. Information on the reason for the call is used for a process within the CRM referred to by staff as "batching". Batching is the process of organizing each profile in the data base is given one subject heading, or batch label, that is expected to summarize the reason for contact. Using this information, staffers can organize contact from citizens into different buckets of information, allowing them to associate different types of citizen contact with different labels. Batching can be automated by the CRM, but staff do not trust the automatic categorization function of the system.

The selection of batching labels varies greatly for each Member's office and what information each office wishes to identify. Sometimes staffers create detailed categories or "batches" for every bill, creating labels along the lines of, 'Pro Bill H.R.1' or 'Con Bill HR.1.' Other times staffers create general batches for information such as 'Supreme Court Hearings', 'Rants', or 'Contact about the President'. Interestingly, staffers associate the level of detail an office or staffer uses to categorize incoming contact with their overall level of engagement with citizen opinion. For example,

P9: "So I would attend other meetings with other [Members' staff] and I got to learn how they batch. And it ranges. They do large batches because they don't really care."

For this participant, the level of detail placed in batching demonstrated the office's willingness to listen to their constituency. If a Member's office labelled citizen input under broad general categories, then those buckets of information would be too large to capture a salience around a topic. If a Member's office created detailed batches, for example delineating differing opinions about a single bill, then that office appeared to care more about the differences in citizen perspective.

Another wrinkle in the efforts to categorize citizen contact come directly from the design of the CRMs themselves. The system limits the degree to staff are encouraged to listen to multiple topics discussed by citizens. As a singular record input, the CRMs require that each record is assigned only one batch label. Thus, if citizens contact Members about more than one topic staff must create additional records or selectively choose which part of the conversation to document. One staffer emphasized,

P2: "They want their voices to be heard, and it's me entering their info into a database."

\subsection{Analyzing Citizen Contact}

Once information from citizen contact is logged in the CRM, the citizen and their opinions become quantifiable data points that can be manipulated and aggregated in specific ways. Staff use these records of citizen communication to track general sentiment, create general measures of citizen interest in a topic, and develop and deploy standardized response. We see minimal evidence of citizen input affecting Members' decision making with regards to policy. As discussed earlier, batching requires assigning one label that is expected to summarize the reason for contact record. Such singular batch labels limit how citizen communication can be analyzed, around questions of general frequency as the primary method of analysis. Such aggregate quantification of citizen contact shapes how citizen communication is used in practice- and how citizens are conceived of as part of the democratic process.

Mail reports are one example of how quantified communication is used in practice. Mail reports are produced by correspondence staff to provide visualizations of information about citizen contact to the Member and their policy staff. These reports can be automatically produced by the CRMs, but many staff produce reports by hand in order to craft reports according to specific information

Proc. ACM Hum.-Comput. Interact., Vol. 3, No. CSCW, Article 47. Publication date: November 2019. 
needs ${ }^{1}$. Surprisingly, these reports often provide minimal information about the reasons citizens contact their Member. Reports pre-dominantly contain information about the efficiency of the correspondence process- detailing the number of total contacts from citizens about an issue per week and/or the letter-writing rates of staff responding to citizens thanking them for their contact. Staff offered mixed opinions about the value of these reports for influencing policy-making. Some staffers believe the number of contacts for a policy topic that is reported in the mail report creates a threshold for potentially taking responsive actions.

P4: "It's a numbers game...The numbers is [sic] the most influential."

P1: "If there's enough people calling, there will be a red light."

These staffers indicate that the Member's office will take notice and act if they are receiving "a lot" of contact about a particular issue. However, staff have difficulty articulating what "a lot" is and what type of action that might be. When pushed, responses are vague, noting that the type of action would depend on the issue and capabilities of the Member.

These anaemic reports are often the only information about citizen opinion that the Member and their policy staff will be exposed to, and they provide only the coarsest insight into citizen concerns. For example, 100 callers communicate to staff their reasons and views on a gun policy, the Member will only see the number of calls for and against the policy. Mail reports do not include information such as why the citizen cares about the policy or what actions the citizen believes the Member should take.

The CRMs render citizens into aggregate data, reducing the value of dialogue and reason-giving by citizens to near zero. Staffers are aware of this tension between being heard and being recorded. Knowing what they do about what the process does to citizen input, they are wary about the value of contacting a representative.

P7: "(I) probably wouldn't call my Representative... I would just be another number in the yes column."

P9: "...honestly I was a little surprised. Because (Congress) get so many calls right? It's more like just data collection. I understand data 'speaks for itself', but still I don't know. I just felt like there was something missing."

The numbers collected in and produced by the CRMs might be perceived as meaningful in aggregate, but staffers are aware that current communication processes de-values the expertise, opinions, and sentiment of citizens. This provides a clear example of the ways in which datafied citizen information renders communication into a process that is less about an exchange of ideas than an exercise in tracking. This is the exact term to describe CRMs- a tool for "sentiment tracking." We suggest that tracking is semantically divergent to listening. Tracking enables surveillance at a surface level, while listening enables the identification of reasons and meaning as a form of insight. Staff support this claim in their use of medicalized phrases when discussing the role of citizen sentiment tracking, such as "taking the temperature" or "measuring the pulse" of citizen opinion.

P43: "Every now and again we overlook a bill that a citizen points out but generally it's for taking temperature."

P38:"(We) use it just to get feedback...It's not necessarily used to make a policy decisions, just to check the pulse of the constituency. You can answer a phone for a day and pretty much know what citizens think."

This language indicates that staffers operate under a logic of recording a metabolic process of citizen sentiment rather than engaging with citizens. The CRMs offers systemic processes for staffers to quantify citizen contact and opinion. But these systems limit the representational capacities

\footnotetext{
${ }^{1}$ Previous research offers substantial empirical descriptions of these mail reports [1]
} 
of data collected during communication with citizens, shaping what actions the staff can take to engage citizen data.

In addition, staff tend to minimize the importance of direct citizen contact based on assumptions of how representative such contact may or may not be. Even if the office receives 500 forms of communication with citizens, staff note there are an average of 700,000 people in the district. Staff find it hard to justify that 500 citizen views might encapsulate the views of the full district. Yet, we find that this perspective is at odds with the complaint that staffers are unable to keep up with the explosion of contact coming into Members' offices. For example, when given a scenario of getting communication from 100,000 citizens, in order to reach a number that the staffer would associate with valuable input, one staffer said their office didn't have the capacity to listen to that many contacts. Thus, we find that the threshold number of citizen calls that might inspire responsive policy-making is not only unspecified but seemingly infeasible based on the capacities of the office to manage citizen communication.

4.2.1 Office Labor. The system of inputting, batching, and analysing citizen data into CRMs is integrally connected to institutional pressures and deployment of labor within Member offices. Here we see how the material conditions of information technology relate to staff labor as it is used to maintain the infrastructure of digitized citizen information. These conditions play a role in the use of CRMs and even the role of the staff in the office.

Batching is a redundant and time-consuming process for correspondence staff. Legislative Correspondents (LCs) are people who read all incoming messages and take all phone calls. They are the front lines of communication as well as the front-end users of the CRM. Staff report spending two to four hours a day manually batching citizen contact into different topics. During high salience issues or after weekends, some staff report spending the entire day batching correspondence by different topic labels.

Much of this low-skilled work is passed down to interns who assist LCs in answering the phone, reading emails, and batching content. Despite being the front lines of citizen communication, these correspondence staff frequently describe their job as having low-value within a Member's office. The culture of congressional staffers assumes that such correspondence jobs are akin to paying one's dues for one to two years before promotion to a higher value job within the office. As one current LC describes,

P48: "The job of the LC is a stepping stone; this job is boring. No one wants this job."

The perceived value of LCs is also reflected in staff responses to questions about how to improve to the correspondence process. During interviews, we asked staff to describe potential improvements to the correspondence technology and process. One correspondence staffer worked on correspondence for over four years, longer than any other staffer interviewed. Despite their expertise, the staffer did not wish to respond to the question, saying that discussing changes to the process was "above my paygrade", and those decisions were done by higher-level staff that do not engage with the CRMs. Clearly such "front line" work is not an arena where staffers are granted autonomy or the ability to engage substantively with citizens. One staffer reflected on their time as an LC on the "front lines" of citizen contact with a mixture of pride and ambivalence.

P9:"I was the front lines, right? So, I kind of appreciated doing that work. But I'm not sure if how I felt... I don't feel like the rest of the office, the permanent staff, have the same perception to citizen concerns. They are very detached. And I didn't appreciate that."

This culture assumes a particular relationship between LCs and CRMs. Correspondence staff are expected to work in order to fulfil the needs the CRM by filling out the expected fields when 
citizens reach out. They are also expected to craft mail reports that are simultaneously conditioned by the constraints of what the CRM is able to do with these data and shaped by Member requestsor what the Member is able to conceive of as useful from these data. Instead of becoming the valued gatekeepers and amplifiers of citizens voices within the office, correspondence staff are rendered data administrators; batching and quantifying citizen opinions with little incentive to engage with citizens, minimal agency in how they present data to higher ups, and no say into how the information they log is used in policy-making.

\subsection{Responding to Citizen Contact}

After citizens communicate with staffers and their record of communication is logged into the database, the LC uses the CRM to craft and send a formal response letter (sent either by email or postal mail). These responses acknowledge that a Members received the citizen's input and appreciates their contact. Response letters generally include information such as the Member's stance on a bill or news about topics the citizen expressed interest in. We find that the processes of producing these responses creates a discursive push towards thinking of citizen relations as a problem of customer service. Such customer service logic reveals itself in the process of responding to citizens. CRMs are, by definition, customer-relations management software. The original CRMs for Congress modified from platforms designed to enhance a business-driven and customer-service experience - one that focuses on "satisfying" and managing customer information over fostering substantive "customer" engagement.

One of the benefits of CRMs for any business is the ability to manage information efficiently. In Congress, Member's offices focus on responding to citizens as quickly as possible in order to assure citizens their correspondence was received. For example, one of the logics of customer-service that is reinforced by the CRM is timeliness. Staff assume that approval and trust in the Member is dependent on speed of reply. Staffers share the widely held opinion that in order to keep citizens happy, they must provide formal responses to citizens in a timely manner.

P1: "You want (responses) at a consistent pace... you do not want to keep (the citizens) hanging."

The speed at which the office responds to citizen contact, also called "turn-around time", is also used as a metric for assessing communication practices and individual staffers.

P21: "We're a two-week turnover. We take it very seriously. At the end of every month we do what's called zero mail day where no mail is allowed to still be in the system. That is rare, but we take it very seriously."

The importance of the turn-around time of responses is also reflected in the CRM's tracking tools. In the two CRMs we analyzed, the dashboard displays on the front page provides staff an overview of how other staff are managing correspondence. The visualizations of the staff's turnaround time lets other staff know who is keeping up with the mail and what mail is backlogged in the office. The display of this information operationalizes the efficiency and effectiveness of the correspondence staff, creating a tool to consistently track performance through response rates. If correspondence staff are behind in responding to letters, other staff can see their progress in the CRM.

Focus on turn-around time has increased with the rise in correspondence from citizens. The limited time capacity of staff means they listen to more contact from citizens and write more responses letters, but they must do so at a faster pace. Despite the larger capacities the CRMs employ to capture, track, and send responses, the system is still limited by the capabilities of the staff to listen, read, batch, and write responses to citizens. We hear the strain in the voices of staffers: 
P2: "When the house is in session sometimes it's hard to leave the phones. You feel chained to your chair. It's hard to take lunch breaks."

P21: "Send as many things as you want but we have a limit of how many things we reply to, it's just like it's our capacity issue."

P4: "It's all me, I find myself stressed a little thin...I'm the only one doing the [response] letters."

To increase efficiency, staff keep a repository of letters in the CRM to use the same content for every letter of similar topic. The letters are also shared with fellow correspondence staff of other Members of the same party. The CRMs gives staffers the ability to create stock responses for mass-messaging. The CRMs provide a platform for the letters to be edited, tracked, and approved by different staff in the correspondence process.

P21: "... if you wrote in a letter on an issue that we don't know anything about and we don't have a letter we've written before than we will then write a new letter. And that letter gets approved first by the letters written by the legislative correspondent, maybe an intern, and then it goes up the system of approval. (The) legislate director approves it, the Chief of Staff approves, and the Member sees it. The Member sees the response letter and does signoff on it. Now they might only see the Net Neutrality letter once, but it's the same content for everyone."

These formal responses act more like thank-you notes than evidence of engaged communication. Often the letters will provide updates on the state of bills or general information about what the Member is already doing to address the issue the citizen discussed. Responses are phrased as the final reply from the Member to the citizen and do not invite further exchange. Two-way communication is a static process where citizens offer their opinion and staff develop letters to thank them for their comments.

In interviews, some staff directly identify correspondence as a customer-oriented process. Such customer-service rhetoric describes a superficial level of engagement which is assumed to make citizens feel like they are listened to without creating the kind of communication exchange that might influence a Member's perspective or actions.

P8: "They always asked different questions, and I always had to kind of put my customer service persona on. Which isn't a big deal, it's not that hard. Like you can't sit there on the phone bored, you have to be engaging and make them feel like they are being listened to."

P10: "We still had to pretend that we cared. As terrible as that sounds, you can't just hang up or say sorry. But you still listen and then you ask them at the end usually ok, can I get your address so we can send some response. Because we always sent, when people called in or mailed in or sent an email or fax, we always responded. You know a thank you letter addressing their concerns, usually an email. That's how they preferred to do it."

Customer service is an essential component to Congress. Members must appear to satisfy citizens desires, or they will not be re-elected. However, as we will discuss further in the discussion, when taken too far, the rhetorical push for satisfaction can deter more participatory forms of engagement that treat citizens as collaborators rather than customers. The CRMs enables staff to respond to citizens at great scales and efficiency. However, such practices deter staff from taking citizen input seriously as a form of policy input. The combination of increased communication from citizens, the capacities of CRMs to monitor and track staff performance, and the CRMs promotion of a 
customer rhetoric place excessive pressure on the correspondence staff to prioritize efficiency of communication over substantive democratic engagement.

\section{DISCUSSION}

Both the social and the material recursively shape and reinforce ideas about the goal of communication in Members offices. This investigation suggests that the materialities of information representation and the material conditions of information technology production around CRMs play a distinct role in how communication between citizens and Members of Congress is realized in practice. The information properties that are most relevant to this investigation are that of granularity and associativity of information [14].

Granularity describes the size of the elements of information recorded in a database. In this case, the granularity of data in the CRMs is the level of detail logged about citizen input. The standard fields of the database ask for three primary pieces of information about the citizen contact (i.e. name, address, reason). The single-issue labels required by CRMs limit the level of detail, thus how granular, a record of citizen communication can be. Granularity is also salient when staffers create their own batching structures within the CRMs and assess each other by the granularity of these structures. When staff batch, they create detailed structure that are seen as "more engaged" by their peers. These insights suggest that the CRM conditions how citizen input is transformed into data by individual staffers and used as aggregate metrics in Member offices. By attending to the materialities of information representation and the conditions of technology use in and through CRMs, we are able to see how the granularity (or lack of granularity) of a data record comes to matter. Granularity ties both to how the communication act unfolds in practice and how the information garnered via communication is used in service of governing.

The material property of associativity is also key in any database. In the CRM, associativity is determined by the batching process. The batch label given to each record of citizen contact allows staff to associate certain records with other records. This labelling process allows staff to aggregate and quantify citizen opinion. CRMs make it easy to run reports on the number of phone calls per day, the number of contacts about a specific bill, or the number of response letters that have been sent to citizens. This configures how staffers associate citizen communication with specific topics or actions. We argue that this process renders each point of contact with a citizen into a quantifiable datapoint rather than an opportunity for engaged communication. Currently, citizen contact is not considered valued input to be listened to. Rather, it is a burden to be logged and responded to with a proforma response. Thus, the numbers control the behaviors [17]. The granular and associative capacities of CRMs align with and solidify this logic into material form.

These customer service database systems also demonstrate the materialities of information technology production. These systems were designed to be customer-driven software to be used by for-profit enterprises, thus prioritizing values of information management and customer satisfaction. Scholarly work has discussed the paradox between treating citizens as customers versus participants in political structures $[3,20,48]$. Such customer service orientations emphasize a "managerial" mode of citizens that prioritizes efficient movement of information, while neglecting participatory modes of engagement [9]. We see this in Congress, where the rhetoric of "customer satisfaction" prevails when staff focus too much on assuaging citizen concerns and satisfying their desire for communication.

Although these material properties of the CRMs play a large role in configuring the ways Members and citizens communicate, the practices of tracking citizen opinion through summarized information is not new to Congress. Staffers have historically documented summaries of volume, position, and tone of contact for particular issues [51] as part of the rise of professional staffing to manage increasing public demands from the 1900 s to 1989 [38]. We cannot say when exactly

Proc. ACM Hum.-Comput. Interact., Vol. 3, No. CSCW, Article 47. Publication date: November 2019. 
these logics for summarization and datafication arose, but they have roots in decades-long practices established by Congress.Decisions made by this body created the environment to which CRMs were introduced. He we see how pre-existing practices engender and institutionalize a particular form of data collection [17] by reinforcing its functionality through a built-in technology feature [68]. Now that tracking of citizen opinion is a functional tool in the technology, it is legitimized as the primary form of documentation of contact between citizens and policymakers, creating a feedback loop for citizen correspondence expectations. Staffers still have some agency over how they document communication - especially when recording summaries of interactions with constituents - but these practices are often shaped by the expectations of the institution just as much as the CRMs. Thus, we see how the social and the material recursively shape and reinforce ideas about the goal of communication with citizens and the value of citizen input.

\subsection{Implications for CSCW}

This work has multiple contributions to the CSCW community. This study makes clear that the datafication of citizen input can affect the nature and experience of communication: how different parties understand the value of communication; what is communicated; and how communication is 'dealt with' organizationally. The perceived legitimacy and value of citizen input is shaped by the communication technologies that datify citizens and their opinions. The way Members of Congress and their staff make sense of and act upon communication from citizens is also configured by the CRMs. From this, we see a tension between idealized narratives of responsive representation and the ways in which CRMs configure communication as a data-driven form of information exchange. The narrative that the rise of communication channels will enable greater dialogue between citizens and their Members is undermined by the fact that citizen communication has become, in effect, an exercise in quantification and data collection.

Previous CSCW research suggests that data-driven technologies can be used as tools that elicit participation and collaboration to support communities and institutions [32]. But in this case, data plays a different role. We find that the tracking of citizen data can drive internal signals of productivity and efficient response practices, rather than providing value for policy decision-making. Such quantification of citizen information relates to scholarly concerns about the rise of numbers as a method of communicating information. Information that has been rendered in numeric form is both anemic and powerful. Numbers are easily communicated and consumed across populations but do not carry contextual information about where the numbers came from and how they were created [55]. Thus, aggregate numeric information about constituent opinion allows Members and staff to engage superficially with citizen opinions. Such representation of citizen voices can be detrimental to democracy, in that it undermines the logics, reasoning, and deliberation required for legitimate political communication.

Technology has reinforced what Members have historically performed (i.e. summarize and track constituent opinion) and legitimized it through an official technology feature. Pressing questions for the $\mathrm{CSCW}$ community are thus, how do we disentangle these complex relationships between policy, representation, and emergent technologies and develop design solutions that could be deployed to enhance communication with representatives? Moving towards what other scholars have suggested [32], there needs to be more work to integrate meaningful forms of engagement where policymakers can trust and act upon citizen engagement, instead of centering their efforts on using technologies that promote passive recognition of citizen input. In addition, our investigation is based on one form of government in the United States and does not reflect the interactions between citizens and their elected representatives in all societies. We also encourage the community to explore these same complex relationships in other governing bodies to understand how they take place in diverse forms of practice. 
There also needs to be more work in CSCW to understand the differences between local and federal policy-making practices. Unlike most studies of citizen engagement in governance that we see in $\mathrm{HCI}$ and CSCW research, our context is not within municipalities of local decision-making. Congress is a massive representative body working within an elaborate network of pressures, demands, and obligations from citizens, advocacy groups, lobbyists, and other governing bodies. Each Member represents an average of 700,000 citizens. Thus, research findings for participatory modes of citizen engagement for a local context may not scale for the purposes of listening to larger representative bodies like those in federal legislatures. These findings may also not translate to societies with different forms of democratic representation. This expansion is essential to understanding how technology practices may overlap or diverge at the local, federal, and societal levels of governance depending on the capacities and of the governing body.

We understand the difficulty to perform these investigations in large institutions. It took multiple years and extensive networking, time, and resources to gain access and trust from employees in Congress. But such efforts toward building trust in these institutions should continue, especially as the field continues to advocate for more policy interaction [41]. This work speaks to the growing body of research at the intersection of policy and HCI. The research community is aware that we have not made significant efforts to engage with public policy-making [41]. However, these scholars call for change center on influencing policy or understanding how policy affects the research community. We suggest that policy and technology researchers can do more than influence the policies enacted by government, by offering transparency of technology's implications for policymaking. Like the growing work in algorithmic transparency, the field is ripe for investigations into the technology used within policy-making environments. This work should increase accountability to ensure technologies are supporting a just and legitimate policy process.

\subsection{Implications for Democracy}

The implications of this work also speak to the fundamental ideals of democratic representation. Through our analysis of the CRM, we highlight competing logics between normative conceptions of political representation and the realities of the everyday work of representation within a representative democracy. The assumption that representatives should be responsive to citizen opinion and collaboratively engage with citizens (ideally via the capacities of new communication technologies) is not demonstrated in the practices of Members' offices. Of course representation comes in many forms. There are multiple conceptions of what legitimate representation looks like in practice [45]. Styles of representation change throughout a representative's decision-making process based on their evolving objectives, situated contingencies, and views of the constituency [18]. Thus styles of communication also shift. Regardless of the style of representation, the needs and the perspectives of citizens should still be taken into account. Yet, this is becoming an increasing challenging with the rise of technologies that control Members' capacity to communicate in the context of growing alienation of citizens, rampant disinformation, and distrust of policymakers in democracies worldwide.

Information and communication technologies have created the expectation that more direct citizen engagement and influence over the policy-making process is possible. But in the case of CRMs, we find the opposite. Such findings contribute to the growing evidence that citizens have little to no input into Member's policy decisions [21]. During a time of declining trust in Congress, such investigations need to be taken seriously in order to understand how the organizational, technological and infrastructural systems in Congress play a role in their how Members incorporate citizen input and make policy decisions. If policy-making institutions continue to promote direct communication and citizen participation, and yet do take that communication seriously in their policy making decisions, then those institutions lack democratic legitimacy [11]. 
Communications technologies like the CRMs do not displace the political realities that already surround institutions, rather they are always intertwined in the conditions of politics [67]. In this case, we see how the materialities of information in the CRMs play a large role in reinforcing historical norms that do not support the democratic legitimacy of the institution. The stakes for the outcomes of this investigation are high; placing the practices of representative democracy at the hands of the communications technologies which mediate relationships between citizens and their policymakers.

\section{CONCLUSION}

We engage a material lens to evaluate three moments during Member-citizen communication where the materiality of the CRMs relates to the representation of citizen information. These moments are (1) during the input of citizen information, (2) the transformation of that information into data for analysis, and (3) the production of written responses to citizens. We find that the ways in which CRMs log and manage information about citizen communication creates discursive expectations that prioritize data-collection and customer satisfaction over substantive engagement. In so doing, CRMs limit the possibility for citizens to be recognized as legitimate actors within the policy-making process. Thus, we offer insight into a case where data-driven technologies elicit pathways for perceived communication and citizen engagement, without inspiring true influence to policy decisions. We find that citizens are continuing to lose their ability to civically engage their policymakers as a result of technological intervention.

\section{ACKNOWLEDGMENTS}

This material is based upon work supported by the National Science Foundation Graduate Research Fellowship under Grant No. (\#DGE-1839285). Any opinions, findings, and conclusions or recommendations expressed in this material are those of the author(s) and do not necessarily reflect the views of the National Science Foundation. This work is also supported by the UCI Center for Organizational Research and the Democracy Fund. We would like to give special thanks to the Congressional Management Foundation for making this work possible and to Paul Dourish for providing valuable insight into the paper.

\section{REFERENCES}

[1] Claire Elizabeth Abernathy. 2015. Legislative Correspondence Management Practices: Congressional Offices and the Treatment of Constituent Opinion. Ph.D. Dissertation. Vanderbilt University.

[2] Ahmer Arif, Leo Graiden Stewart, and Kate Starbird. 2018. Acting the part: Examining information operations within\# blacklivesmatter discourse. Proceedings of the ACM on Human-Computer Interaction 2, CSCW (2018), 20.

[3] Ulrich Beck. 1997. The reinvention of politics: rethinking modernity in the global social order. Polity Press ; Blackwell Publishers, Cambridge, UK : Cambridge, MA. OCLC: ocm35673555.

[4] Paul Beynon-Davies and Steve Martin. 2004. Electronic local government and the modernisation agenda: Progress and prospects for public service improvement. Local government studies 30, 2 (2004), 214-229.

[5] Bruce A Bimber. 2003. Information and American democracy: technology in the evolution of political power. Cambridge University Press, Cambridge, U.K.; New York. http://site.ebrary.com/id/10461902 OCLC: 726828083.

[6] Nina Boulus-Rødje, Pernille Bjørn, and Ahmad Ghazawneh. 2015. "It's About Business not Politics": Software Development Between Palestinians and Israelis. In ECSCW 2015: Proceedings of the 14th European Conference on Computer Supported Cooperative Work, 19-23 September 2015, Oslo, Norway, Nina Boulus-Rødje, Gunnar Ellingsen, Tone Bratteteig, Margunn Aanestad, and Pernille Bjørn (Eds.). Springer International Publishing, Cham, 43-61.

[7] Anne Bowser, Derek Hansen, Jennifer Preece, Yurong He, Carol Boston, and Jen Hammock. 2014. Gamifying Citizen Science: A Study of Two User Groups. In Proceedings of the Companion Publication of the 17th ACM Conference on Computer Supported Cooperative Work \&\#38; Social Computing (CSCW Companion '14). ACM, New York, NY, USA, 137-140. https://doi.org/10.1145/2556420.2556502

[8] Andrew Chadwick. 2011. Explaining the failure of an online citizen engagement initiative: The role of internal institutional variables. Journal of Information Technology \& Politics 8, 1 (2011), 21-40. 
[9] Andrew Chadwick and Christopher May. 2003. Interaction between States and Citizens in the Age of the Internet:"eGovernment" in the United States, Britain, and the European Union. Governance 16, 2 (2003), 271-300.

[10] Steven L Clift. 2004. E-government and Democracy. http://stevenclift.com/wp-content/uploads/2009/05/ cliftegovdemocracy.pdf

[11] Stephen Coleman. 2017. Can the internet strengthen democracy? Polity Press, Cambridge, UK ; Malden, MA, USA.

[12] Eric Corbett and Christopher A. Le Dantec. 2018. Going the Distance: Trust Work for Citizen Participation. In Proceedings of the 2018 CHI Conference on Human Factors in Computing Systems (CHI '18). ACM, New York, NY, USA, Article 312, 13 pages. https://doi.org/10.1145/3173574.3173886

[13] Dharma Dailey and Kate Starbird. 2017. Social Media Seamsters: Stitching Platforms; Audiences into Local Crisis Infrastructure. In Proceedings of the 2017 ACM Conference on Computer Supported Cooperative Work and Social Computing (CSCW '17). ACM, New York, NY, USA, 1277-1289. https://doi.org/10.1145/2998181.2998290

[14] Paul Dourish. 2017. The stuff of bits: an essay on the materialities of information. The MIT Press, Cambridge, Massachusetts.

[15] Paul Dourish and Melissa Mazmanian. 2013. Media as Material: Information Representations as Material Foundations for Organizational Practice. In How Matter Matters, Paul R. Carlile, Davide Nicolini, Ann Langley, and Haridimos Tsoukas (Eds.). Oxford University Press, 92-118. https://doi.org/10.1093/acprof:oso/9780199671533.003.0005

[16] James N. Druckman, Martin J. Kifer, and Michael Parkin. 2007. The Technological Development of Congressional Candidate Web Sites: How and Why Candidates Use Web Innovations. Social Science Computer Review 25, 4 (2007), 425-442. https://doi.org/10.1177/0894439307305623

[17] Wendy Nelson Espeland and Mitchell L Stevens. 2008. A sociology of quantification. European fournal of Sociology/Archives Européennes de Sociologie 49, 3 (2008), 401-436.

[18] Richard F Fenno. 1978. Home style: House members in their districts. HarperCollins,

[19] Open Gov Foundation. 2018. From Voicemail to Votes: human-centered investigation by The OpenGov Foundation into the systems, tools, constraints, and people who drive constituent engagement in Congress. https: //v2v.opengovfoundation.org/

[20] Jane E. Fountain. 2001. Building the Virtual State: Information Technology and Institutional Change. Brookings Institution Press. http://www.jstor.org/stable/10.7864/j.ctvcb59n3

[21] Martin Gilens and Benjamin I. Page. 2014. Testing Theories of American Politics: Elites, Interest Groups, and Average Citizens. Perspectives on Politics 12, 3 (2014), 564-581. https://doi.org/10.1017/S1537592714001595

[22] Matthew Eric Glassman, Jacob R Straus, and Colleen J Shogan. 2013. Social networking and constituent communications: members' use of Twitter and Facebook during a two-month period in the 112th Congress.

[23] Jennifer Golbeck, Justin M. Grimes, and Anthony Rogers. 2010. Twitter use by the U.S. Congress. Fournal of the American Society for Information Science and Technology 61, 8 (2010), 1612-1621. https://doi.org/10.1002/asi.21344 arXiv:https://onlinelibrary.wiley.com/doi/pdf/10.1002/asi.21344

[24] Kathy Goldschmidt. 2011. Communicating with Congress: Perceptions of citizen advocacy on Capitol Hill.

[25] Åke Grönlund. 2003. Emerging electronic infrastructures: Exploring democratic components. Social science computer review 21,1 (2003), 55-72.

[26] Mike Harding, Bran Knowles, Nigel Davies, and Mark Rouncefield. 2015. HCI, Civic Engagement; Trust. In Proceedings of the 33rd Annual ACM Conference on Human Factors in Computing Systems (CHI '15). ACM, New York, NY, USA, 2833-2842. https://doi.org/10.1145/2702123.2702255

[27] Brent Hecht, Loren Terveen, Kate Starbird, Ben Shneiderman, and Jennifer Golbeck. 2017. The 2016 US Election and HCI: Towards a Research Agenda. In Proceedings of the 2017 CHI Conference Extended Abstracts on Human Factors in Computing Systems (CHI EA '17). ACM, New York, NY, USA, 1307-1311. https://doi.org/10.1145/3027063.3051140

[28] Libby Hemphill and Andrew J. Roback. 2014. Tweet Acts: How Constituents Lobby Congress via Twitter. In Proceedings of the 17th ACM Conference on Computer Supported Cooperative Work \&\#38; Social Computing (CSCW '14). ACM, New York, NY, USA, 1200-1210. https://doi.org/10.1145/2531602.2531735

[29] Tim Hysom. 2008. Communicating with Congress: recommendations for improving the democratic dialogue. Congressional Management Foundation.

[30] Steven J. Jackson, Tarleton Gillespie, and Sandy Payette. 2014. The Policy Knot: Re-integrating Policy, Practice and Design in Cscw Studies of Social Computing. In Proceedings of the 17th ACM Conference on Computer Supported Cooperative Work; Social Computing (CSCW '14). ACM, New York, NY, USA, 588-602. https://doi.org/10.1145/2531602. 2531674

[31] Steven J. Jackson, Stephanie B. Steinhardt, and Ayse Buyuktur. 2013. Why CSCW Needs Science Policy (and Vice Versa). In Proceedings of the 2013 Conference on Computer Supported Cooperative Work (CSCW'13). ACM, New York, NY, USA, 1113-1124. https://doi.org/10.1145/2441776.2441902

[32] Ian G. Johnson, Aare Puussaar, Jennifer Manuel, and Peter Wright. 2018. Neighbourhood Data: Exploring the Role of Open Data in Locally Devolved Policymaking Processes. Proc. ACM Hum.-Comput. Interact. 2, CSCW, Article 83 (Nov. 
2018), 20 pages. https://doi.org/10.1145/3274352

[33] Sarah Kaplan. 2011. Strategy and PowerPoint: An inquiry into the epistemic culture and machinery of strategy making Organization Science 22, 2 (2011), 320-346.

[34] David Karpf. 2010. Online political mobilization from the advocacy group's perspective: Looking beyond clicktivism. Policy \& Internet 2, 4 (2010), 7-41.

[35] Jofish Kaye, Casey Fiesler, Neha Kumar, and Bryan Semaan. 2017. Policy Impacts on the HCI Research Community. In Proceedings of the 2017 CHI Conference Extended Abstracts on Human Factors in Computing Systems (CHI EA '17). ACM, New York, NY, USA, 1300-1302. https://doi.org/10.1145/3027063.3051706

[36] Sunyoung Kim, Jennifer Mankoff, and Eric Paulos. 2013. Sensr: Evaluating a Flexible Framework for Authoring Mobile Data-collection Tools for Citizen Science. In Proceedings of the 2013 Conference on Computer Supported Cooperative Work (CSCW'13). ACM, New York, NY, USA, 1453-1462. https://doi.org/10.1145/2441776.2441940

[37] Peter Kinnaird, Mario Romero, and Gregory Abowd. 2010. Connect 2 Congress: Visual Analytics for Civic Oversight. In CHI '10 Extended Abstracts on Human Factors in Computing Systems (CHI EA '10). ACM, New York, NY, USA, 2853-2862. https://doi.org/10.1145/1753846.1753872

[38] Kevin Kosar. 2019. Congressional Staff Trends. https://www.hillhappenings.com/list/2018/9/5/ capitol-historical-society-lecture-congressional-staffing-trends Remarks by Kevin Kosar presented at the Capitol Historical Society Lecture in Washington, DC.

[39] Travis Kriplean, Jonathan Morgan, Deen Freelon, Alan Borning, and Lance Bennett. 2012. Supporting Reflective Public Thought with Considerit. In Proceedings of the ACM 2012 Conference on Computer Supported Cooperative Work (CSCW '12). ACM, New York, NY, USA, 265-274. https://doi.org/10.1145/2145204.2145249

[40] Jennifer L Lawless. 2012. Becoming a candidate: Political ambition and the decision to run for office. Cambridge University Press.

[41] Jonathan Lazar, Julio Abascal, Simone Barbosa, Jeremy Barksdale, Batya Friedman, Jens Grossklags, Jan Gulliksen, Jeff Johnson, Tom McEwan, LoÃŕc MartÃynez-Normand, Wibke Michalk, Janice Tsai, Gerrit van der Veer, Hans von Axelson, Ake Walldius, Gill Whitney, Marco Winckler, Volker Wulf, Elizabeth F. Churchill, Lorrie Cranor, Janet Davis, Alan Hedge, Harry Hochheiser, Juan Pablo Hourcade, Clayton Lewis, Lisa Nathan, Fabio Paterno, Blake Reid, Whitney Quesenbery, Ted Selker, and Brian Wentz. 2016. Human-Computer Interaction and International Public Policymaking: A Framework for Understanding and Taking Future Actions. Foundations and Trends in Human-Computer Interaction 9 , 2 (2016), 69-149. https://doi.org/10.1561/1100000062

[42] Hanlin Li, Bodhi Alarcon, Sara Milkes Espinosa, and Brent Hecht. 2018. Out of Site: Empowering a New Approach to Online Boycotts. Proc. ACM Hum.-Comput. Interact. 2, CSCW, Article 106 (Nov. 2018), 28 pages. https://doi.org/10. $1145 / 3274375$

[43] Silvia Lindtner and Seyram Avle. 2017. Tinkering with Governance: Technopolitics and the Economization of Citizenship. Proc. ACM Hum.-Comput. Interact. 1, CSCW, Article 70 (Dec. 2017), 18 pages. https://doi.org/10.1145/ 3134705

[44] Daniel Lipinski. 2009. Congressional communication: Content and consequences. University of Michigan Press.

[45] Jane Mansbridge. 2003. Rethinking Representation. American Political Science Review 97, 4 (Nov. 2003), 515-528. https://doi.org/10.1017/S0003055403000856

[46] Viktor Mayer-Schönberger and David Lazer. 2007. From electronic government to information government. Governance and information technology: From electronic government to information government (2007), 1-14.

[47] Ines Mergel. 2012. The social media innovation challenge in the public sector. Information Polity 17, 3, 4 (2012), 281-292.

[48] Tina Nabatchi and Matt Leighninger. 2015. Public participation for 21st century democracy. John Wiley \& Sons.

[49] Michael A Neblo, Kevin M Esterling, and David Lazer. 2018. Politics with the people: building a directly representative democracy. Vol. 555. Cambridge University Press. https://doi.org/10.1017/9781316338179 OCLC: 1057675166.

[50] Wanda J Orlikowski. 2007. Sociomaterial practices: Exploring technology at work. Organization studies 28, 9 (2007), $1435-1448$.

[51] Diana Owen, Richard Davis, and Vincent James Strickler. 1999. Congress and the Internet. Harvard International Journal of Press/Politics 4, 2 (1999), 10-29. https://doi.org/10.1177/1081180X99004002003

[52] Leysia Palen and Sophia B. Liu. 2007. Citizen Communications in Crisis: Anticipating a Future of ICT-supported Public Participation. In Proceedings of the SIGCHI Conference on Human Factors in Computing Systems (CHI '07). ACM, New York, NY, USA, 727-736. https://doi.org/10.1145/1240624.1240736

[53] Sofie Pilemalm. 2018. Participatory Design in Emerging Civic Engagement Initiatives in the New Public Sector: Applying PD Concepts in Resource-Scarce Organizations. ACM Trans. Comput.-Hum. Interact. 25, 1, Article 5 (Jan. 2018), 26 pages. https://doi.org/10.1145/3152420

[54] Hanna F Pitkin. 1967. The concept of representation. Vol. 75. Univ of California Press. 
[55] Theodore M Porter. 2001. Trust in Numbers: the Pursuit of Objectivity in Science and Public Life. Princeton University Press, Princeton. https://doi.org/10.1515/9781400821617 OCLC: 700688673.

[56] Christine Robson, Marti Hearst, Chris Kau, and Jeffrey Pierce. 2013. Comparing the Use of Social Networking and Traditional Media Channels for Promoting Citizen Science. In Proceedings of the 2013 Conference on Computer Supported Cooperative Work (CSCW '13). ACM, New York, NY, USA, 1463-1468. https://doi.org/10.1145/2441776.2441941

[57] Daniela K. Rosner. 2012. The Material Practices of Collaboration. In Proceedings of the ACM 2012 Conference on Computer Supported Cooperative Work (CSCW'12). ACM, New York, NY, USA, 1155-1164. https://doi.org/10.1145/2145204.2145375

[58] Dana Rotman, Jen Hammock, Jenny J. Preece, Carol L. Boston, Derek L. Hansen, Anne Bowser, and Yurong He. 2014 Does Motivation in Citizen Science Change with Time and Culture?. In Proceedings of the Companion Publication of the 17th ACM Conference on Computer Supported Cooperative Work; Social Computing (CSCW Companion '14). ACM, New York, NY, USA, 229-232. https://doi.org/10.1145/2556420.2556492

[59] Colleen J. Shogan. 2010. Blackberries, Tweets, and YouTube: Technology and the Future of Communicating with Congress. PS: Political Science \& Politics 43, 2 (2010), 231-233. https://doi.org/10.1017/S1049096510000041

[60] Stuart W Shulman. 2009. The case against mass e-mails: Perverse incentives and low quality public participation in US federal rulemaking. Policy \& Internet 1, 1 (2009), 23-53.

[61] SIGCHI 2018. Proceedings of CSCW'18: The 2018 ACM Conference on Computer Supported Cooperative Work and Social Computing. SIGCHI, ACM, New York, NY, USA.

[62] Vanessa Thomas, Christian Remy, Mike Hazas, and Oliver Bates. 2017. HCI and Environmental Public Policy: Opportunities for Engagement. In Proceedings of the 2017 CHI Conference on Human Factors in Computing Systems (CHI '17). ACM, New York, NY, USA, 6986-6992. https://doi.org/10.1145/3025453.3025579

[63] Arjuna Tuzzi, Claudia Padovani, and Giorgia Nesti. 2002. Communication and (e) democracy: assessing European e-democracy discourses. IDEA (2002), 13.

[64] Amy Voida, Lynn Dombrowski, Gillian R. Hayes, and Melissa Mazmanian. 2014. Shared Values/Conflicting Logics: Working Around e-Government Systems. In Proceedings of the SIGCHI Conference on Human Factors in Computing Systems (CHI '14). ACM, New York, NY, USA, 3583-3592. https://doi.org/10.1145/2556288.2556971

[65] Ken Ward and Zach Graves. 2019. Doing Business With Congress: A Primer on Information Technology Acquisitions in the Legislative Branch.

[66] Andrea Wiggins and Kevin Crowston. 2011. From Conservation to Crowdsourcing: A Typology of Citizen Science. In Proceedings of the 2011 44th Hawaii International Conference on System Sciences (HICSS '11). IEEE Computer Society, Washington, DC, USA, 1-10. https://doi.org/10.1109/HICSS.2011.207

[67] Langdon Winner. 1980. Do artifacts have politics? Daedalus (1980), 121-136.

[68] Joann Yates and Wanda Orlikowski. 2007. The PowerPoint presentation and its corollaries: How genres shape communicative action in organizations. Communicative practices in workplaces and the professions: Cultural perspectives on the regulation of discourse and organizations 1 (2007), 67-92.

[69] Bo Yu and Guoray Cai. 2009. Facilitating Participatory Decision-making in Local Communities Through Map-based Online Discussion. In Proceedings of the Fourth International Conference on Communities and Technologies. ACM, New York, NY, USA, 215-224. https://doi.org/10.1145/1556460.1556492

Received April 2019; revised June 2019; accepted August 2019 